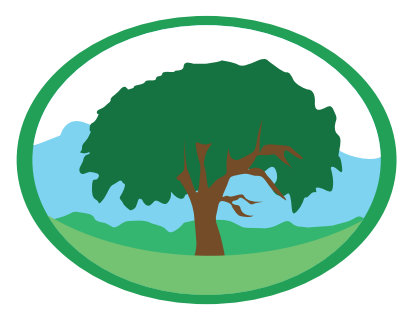

\title{
Estudo de Viabilidade Econômica da Adequação e Revitalização de uma Agroindústria de Cachaça Artesanal
}

ZANELLA,MARCO ANTONIO'; DOMINGUES NETO,JAIME DA ROSA' ; LUZ,MARIA LAURA GOMES

SILVA DA²;GADOTTI,GIZELE INGRID²;LUZ,CARLOS ALBERTO SILVEIRA DA²; PEREIRA, BERNARDO

RODRIGUES ${ }^{3}$; ROCHA, GEAN NASCIMENTO³; MORAES, PHILIPPE BRAGA ${ }^{3}$

'Engenheiro Agrícola - marko_zanella@ahotmail.com; jaimerdnetolahotmail.com

${ }^{2}$ Prof.- CEng -Universidade Federal de Pelotas - m.lauraluzQgmail.com

${ }^{3}$ Acadêmico - Eng. Agrícola - UFPel

Palavras-chave: bebida

alcoólica, produção artesanal, agroindústria

\section{RESUMO}

Este trabalho foi um estudo de caso em uma empresa familiar que produz cachaça desde 1945 e vem passando de geração em geração, produzindo uma cachaça reconhecida pelo sabor e pela coloração azul, proveniente da folha de bergamota colocada na cabeça do alambique. A atual produção de cachaça é comercializada no mercado informal e consiste numa atividade complementar à renda do produtor rural. Este estudo teve o objetivo de avaliar a viabilidade da adequação desta agroindústria de pequeno porte, localizada no interior do município de Cristal, que produzirá 3500 litros/ano de cachaça, sendo 30\% da produção envelhecida em pipas de carvalho. A adequação da produção visa à conformidade com a legislação vigente. 0 estudo de viabilidade técnica das adequações da agroindústria de cachaça artesanal apresentou viabilidade, mostrando que pequenas adequações podem permitir o enquadramento de um produtor artesanal nas especificações legais. 0 estudo de viabilidade econômica apresentou Taxas Internas de Retorno (TIR) distintas nos diferentes cenários, demonstrando a sensibilidade da variação do preço da cachaça na viabilidade do projeto. Comparados com uma TMA (Taxa Mínima de Atratividade), de 14\%, os cenários apresentaram condições de viabilizar o projeto. Com o preço de venda de $\mathrm{R} \$ 23,00$ para a cachaça tipo Prata e de R\$ 34,12 para a tipo Premium o projeto equilibrou as finanças, determinando assim o preço mínimo de comercialização para a quantidade produzida. Considerando o IPI (Imposto sobre Produtos Industrializados) há uma redução da TIR para 18\%.

\section{Economic Viability Study of Adequacy and Revitalization of a HandcraftAgro-industry of Cachaça}

Keywords: alcoholic beverages, handicraft production, agroindustry

\begin{abstract}
This study was a case study in a family business producing cachaça since 1945 and has been passed from generation to generation. Early in its history, the cachaça was recognized by the taste and the blue color, color came from a peculiar technique. The preparation of the blue cachaça is to add a bergamot branch's head still. The current production of cachaça is sold in the informal market and is a complementary activity to the income of farmers. This project aimed to study the feasibility of the adequacy of a small agribusiness that will produce $3500 \mathrm{~L} / \mathrm{year}$ of cachaça, $30 \%$ of production aged in oak barrels. The adequacy of the production is aimed at compliance the legal requirements. The technical feasibility study of the adequacy of cachaça agribusiness presented viability, showing that small
\end{abstract}


adjustments can enable the inclusion of an artisan producer in the legal specifications. The economic feasibility study of cachaça agribusiness presented Internal Rates of Return (IRR) different in different scenarios, demonstrating the sensitivity of cachaça price change in the project's viability. Compared toMinimum Attract Tax14\%, the scenarios presented able to make the project viable. With the selling price of $\mathrm{R} \$ 23.00$ for the silver type cachaca and R\$34.12 for Premium type, the project balanced finances, thus determining the minimum sale price for the quantity produced.

\section{INTRODUCุÃO}

A cachaça consagrou-se como bebida nacional através do Decreto $\mathrm{N}^{\circ} 4062$, de 21 de dezembro de 2001, o qual define as expressōes "cachaça" e "cachaça do Brasil" como indicaçôes geográficas, estando intimamente ligada com a cultura do país. Para os historiadores não há dúvidas quanto ao fato da cachaça ter sido destilada, pela primeira vez, em engenhos do litoral brasileiro, tendo suas origens na época do Brasil colônia(SOUZA et al., 2013).

A Instrução Normativa № 13, de 29 de junho de 2005, do Ministério da Agricultura, Pecuária e Abastecimento (MAPA) estabelece os Padróes de Identidade e Qualidade (PIQ) para aguardente de canade-açúcar e para cachaça, esta que é a denominação típica e exclusiva da aguardente de cana produzida no Brasil. Bebida com graduaçáo alcoólica de 38 a $48 \%$ em volume (a $20^{\circ} \mathrm{C}$ ); obtida pela destilação do mosto fermentado do caldo de cana-de-açúcar com características sensoriais peculiares, podendo ser adicionada de açúcares até seis gramas por litro.

A cachaça artesanal diferencia-se da industrial náo apenas por sua escala de produção, mas também por suas características sensoriais. Por ser destilada normalmente em alambiques de cobre, nas pequenas propriedades rurais, pode apresentar melhor qualidade sensorial do que uma cachaça industrial (SILVA et al., 2005). Além disso, há um crescente segmento em que predominam empresas pequenas e médias as quais utilizaçáo a diferenciação do produto para ter competitividade no setor, oferecendo produtos destinados ao público de maior poder aquisitivo, e mais exigentes quanto a consumir um produto diferenciado, assim atingindo maior rentabilidade diante de uma produção pequena.

A oferta da cachaça Premium também tem aumentado, uma vez que o principal benefício do envelhecimento da cachaça é o aprimoramento da qualidade química e sensorial da bebida, além de agregar maior valor comercial ao produto (SOUZA et al., 2013).

$\mathrm{O}$ aumento da demanda do mercado consumidor por produtos de maior qualidade está desafiando produtores a buscar a modernização e a padronizaçáo dos processos de produçáo de bebidas. Apesar de ser um processo simples, a fabricação da cachaça é dividida em várias etapas e considerando que é produzida em diversas regiōes do Brasil, possibilita a criação de uma variedade extensa de aromas e sabores.

A produção de cachaça modificou-se ao longo do tempo. Os alambiques artesanais, instalados nas fazendas com produção destinada ao consumo interno, abriram espaço para alambiques industriais, que exportam seu produto para todas as partes do país e do exterior.

Atualmente, várias marcas de alta qualidade figuram no comércio nacional e internacional, estando presentes nos melhores restaurantes e adegas residenciais do Brasil e do mundo, conforme vários programas culinários.Neste cenário há espaço para as cachaças artesanais que mantêm as características deste tipo de produto.

Segundo dados do Instituto Brasileiro da Cachaça (IBRAC, 2015), o Brasil possui quase 2.000 produtores devidamente registrados, com 4.000 marcas. Com uma capacidade de produção instalada estimada em aproximadamente 1,2 bilháo de litros anuais da bebida, porém, anualmente são produzidos aproximadamente 800 milhôes de litros.Em 2001, a cachaça consagrou-se como bebida nacional com o Decreto ${ }^{\circ} 4062$ de 21 de dezembro deste ano, o qual define as expressōes "cachaça" e "cachaça do Brasil" como indicaçōes geográficas. Em 2014, a cachaça foi exportada para 66 países. Sáo mais de 60 empresas exportadoras, gerando uma receita de US\$ 18,33 milhôes (10,18 milhōes de litros). Comparando-se os números de 2014, houve um aumento de mais de $10 \%$ em relação a 2013. Também houve um aumento de mais de $10 \%$ no volume de litros exportados em 2014 (IBRAC, 2015).

A cana-de açúcar é a matéria prima para produção 
da cachaça. Para garantir a qualidade da cana devem-se ter alguns cuidados na hora da colheita. A deterioração da cana é de natureza enzimática, química e microbiológica, iniciando logo após o corte. De uma maneira geral, a cana deve passar pelo processo de moagem em até 24 horas após o corte. Deste modo, as características fitossanitárias da cana contribuem para menores interferências no processo industrial e com melhores rendimentos (OLIVEIRA et al., 2005).

A moagem visa a melhorar a extração do caldo, sendo a etapa mais importante que governa o rendimento do processo produtivo, e tem o objetivo de recuperar o açúcar dissolvido no caldo, armazenado nos tecidos de reserva ou células parenquimatosas dos colmos da cana-de-açúcar.O caldo extraído pelas moendas é filtrado e decantado para remoção de impurezas (MUTTON; MUTTON, 2010).

O mosto é então fermentado e após destilado para obtenção da cachaça. $\mathrm{O}$ principal benefício do envelhecimento da cachaça é o aprimoramento da qualidade química e sensorial da bebida, além de agregar maior valor comercial ao produto (SOUZA et al., 2013).

Este trabalho foi um estudo de caso de uma empresa familiar que produz cachaça desde 1945 e vem passando de geração em geração.No início de sua história, a cachaça era reconhecida pelo sabor e pela coloração azul, cor que provinha de uma técnica peculiar. O preparo da cachaça azul consiste em adicionar um galho de bergamota na cabeça do alambique. A atual produção de cachaça é obtida a partir de cana-de-açúcar de produção própria, comercializada no mercado informal e consiste numa atividade complementar à renda do produtor rural.

A análise econômica fornece os indicadores de viabilidade que possibilitam a tomada de decisão do investidor sobre o investimento de recursos financeiros em um dado projeto. Estes indicadores de viabilidade são: Taxa Mínima de Atratividade (\%), Valor Presente Líquido (R\$), Taxa Interna de Retorno (\%), Taxa Interna de Retorno modificada (\%) e payback(anos) (BUARQUE, 1991; KOTLER, 1992; CASAROTTO FILHO; KOPITTKE, 2000).

A Taxa Mínima de Atratividade (TMA) é a taxa de juros em geral oferecida por instituiçóes financeiras (bancos), que representa um mínimo que um investidor se propóe a ganhar quando faz um investimento, o Valor Presente Líquido (VPL) é o cálculo que determina o valor presente de pagamentos futuros descontados a uma taxa de juros apropriada, menos o custo do investimento inicial; a Taxa Interna de Retorno (TIR) é uma taxa de desconto hipotética que, quando aplicada a um fluxo de caixa, faz com que os valores das despesas trazidos ao valor presente seja igual aos valores dos retornos do investimento; a Taxa Interna de Retorno Modificada (TIRm) é semelhante à TIR, porém esta considera o custo do dinheiro tomado como empréstimo para financiar o empreendimento e entende que o dinheiro gerado é reinvestido no negócio e o paybacké o tempo decorrido entre o investimento inicial e o momento no qual o lucro líquido acumulado se iguala ao valor desse investimento (BUARQUE, 1991; KOTLER, 1992; CASAROTTO FILHO; KOPITTKE, 2000).

Este estudo teve o objetivo de avaliar a viabilidade da adequação de uma agroindústria de pequeno porte, localizada no interior do município de Cristal que produzirá 3500 litros/ano de cachaça, sendo 30\% da produção envelhecida em pipas de carvalho. A adequação da produção visa à conformidade com o Decreto No 4.062, de 21 de dezembro de 2001 (conhecido como Lei de Cachaça) e a Instrução Normativa $\mathrm{N}^{\circ}$ 13, de 29 de junho de 2005, a Instrução Normativa $N^{\circ} 15$, de 31 de março de 2011 e a Instrução Normativa $\mathrm{N}^{\circ} 17$, de 23 de junho de 2015, que apresenta uma listagem a ser cumprida para o registro de estabelecimento.

\section{MATERIAL E MÉTODOS}

Este estudo de revitalização e adequação da agroindústria de cachaça, localizada no município de Cristal-RS, foi direcionado a um produtor que possui uma propriedade de 28 hectares, sendo cerca de 10 hectares destinados para a produçáo de cana-deaçúcar, que é a matéria prima para produzir cachaça. Sua capacidade de produção é de 3500 litros/ano, e aproximadamente 30\% da produção será armazenada em pipas de carvalho para ser envelhecida.

Inicialmente, foi realizada a análise de teor alcoólico da cachaça produzida, no laboratório LEPC (CEng- 
UFPel), com o objetivo de avaliar se o produto possui o teor exigido nas normas para ser considerado cachaça. As amostras foram dispostas em provetas graduadas de $50 \mathrm{~mL}$ e a leitura do teor alcóolico realizada através de um alcoômetro (densímetro) e sua leitura em ${ }^{\circ} \mathrm{GL}$ (Gay Lussac).

Foi também realizado um fluxograma com balanço de massa para auxiliar na elaboração de investimentos e custos. A partir deste fluxograma, com as operaçóes unitárias envolvidas na produçáo da cachaça, adequado à capacidade de produção em termos de equipamentos e mão-de-obra, foram planejadas as adequaçóes conforme a Instrução Normativa (IN) $\mathrm{N}^{\circ}$ 13, queestabelece os Padróes de Identidade e Qualidade (PIQ) para aguardente de cana-de-açúcar e para cachaça, a qual foi parcialmente alterada pela IN No 58, de 19 dezembro de 2007 e pela IN No 27, de 15 de maio de 2008.

Foi proposta uma adequação no layout da empresa para produção de cachaças tipo Prata e tipo Premium, que deverá, antes do início de qualquer construção, ter seu Projeto Sanitário aprovado pelo MAPA, em função da Instrução Normativa No 17, de 23/06/2015 e da Instrução Normativa № 5, de 31/03/2000, que trata das Boas Práticas de Fabricação, que fazem parte de um checklist, quenecessitaráser preenchido, como requisitos, para obter o Licenciamento Sanitário do estabelecimento.Além disso, foi criada uma marca própria com rótulo e embalagem (que também deve ser aprovado pelo MAPA), objetivando lançar no mercado um produto diferenciado com características exclusivas do produtor, valorizando o segmento das bebidas artesanais e a cultura local.

Foi realizado o orçamento dos equipamentos e das obras civil necessárias para realizar a adequação dos locais de trabalho e também foram calculados os custos fixos e variáveis para produção. $\mathrm{O}$ orçamento não contemplou o Projeto Sanitário, a ser aprovado pelo órgão competente, bem como o Projeto Ambiental, que também deverá ser aprovado pelo município ou pela FEPAM - Fundação Estadual de Proteção Ambiental, caso o município não tenha a outorga para realizar este tipo de trabalho. Também não foi computado o Licenciamento Tributário/Fiscal e o Plano de Prevenção contra incêndio - PPCI.Através desses dados foi realizada a análise econômica das modificaçóes, sendo as variáveis os preços de venda das cachaças tipo Prata e tipo Premium.

Foi realizada uma pesquisa de mercado com consumidores de cachaça para entender detalhes sobre o produto.

Como parte do estudo de mercado, foi traçada a matriz de SWOT, que consiste numa metodologia utilizada para promover a análise de cenários, comumente utilizada em empresas (KOTLER, 1992).

O Canvas Business Model é uma ferramenta de gerenciamento estratégico, que permite desenvolver e esboçar modelos de negócio novos ou existentes. $\mathrm{O}$ modelo apresentado neste trabalho é uma adaptação de Finocchio Júnior (2013) que visa a tornar possível a análise e reflexão sobre o modelo de negócio e as partes envolvidas.

Então, foi realizada a análise econômica do projeto, para um horizonte de planejamento de 10 anos, através dos índices econômico-financeiros: VPL (Valor Presente Líquido), TIR (Taxa Interna de Retorno), TIRm (TIR modificada) e payback (tempo de retorno do capital investido) (BUARQUE, 1991; CASAROTTO FILHO; KOPITTKE, 2000). A Taxa Mínima de Atratividade (TMA) considerada foi de $14 \%$.

Foram elaborados quatro cenários econômicos, os quais podem refletir um cenário real de variação de preço para a perspectiva de 10 anos.

Considerado um cenário real, foram estabelecidos preços obtidos a partir da média de preços observados aos praticados no mercado para as cachaças tipo Prata e tipo Premium. Para o cenário pessimista, os preços da cachaça foram considerados os valores mínimos para que o produtor trabalhe sem prejuízos. Em um cenário otimista foram considerados valores equivalentes aos observados pelas melhores cachaças do mercado. O quarto cenário considera que incide sobre a produção o IPI atualmente cobrado.

\section{RESULTADOS E DISCUSSÃO}

A pesquisa de mercado mostrou que grandes marcas de aguardente industrial são vendidas nos mercados de Pelotas a preços entre $\mathrm{R} \$ 6,00$ e 8,00 a garrafa. No entanto, as cachaças artesanais ou que são produzidas 


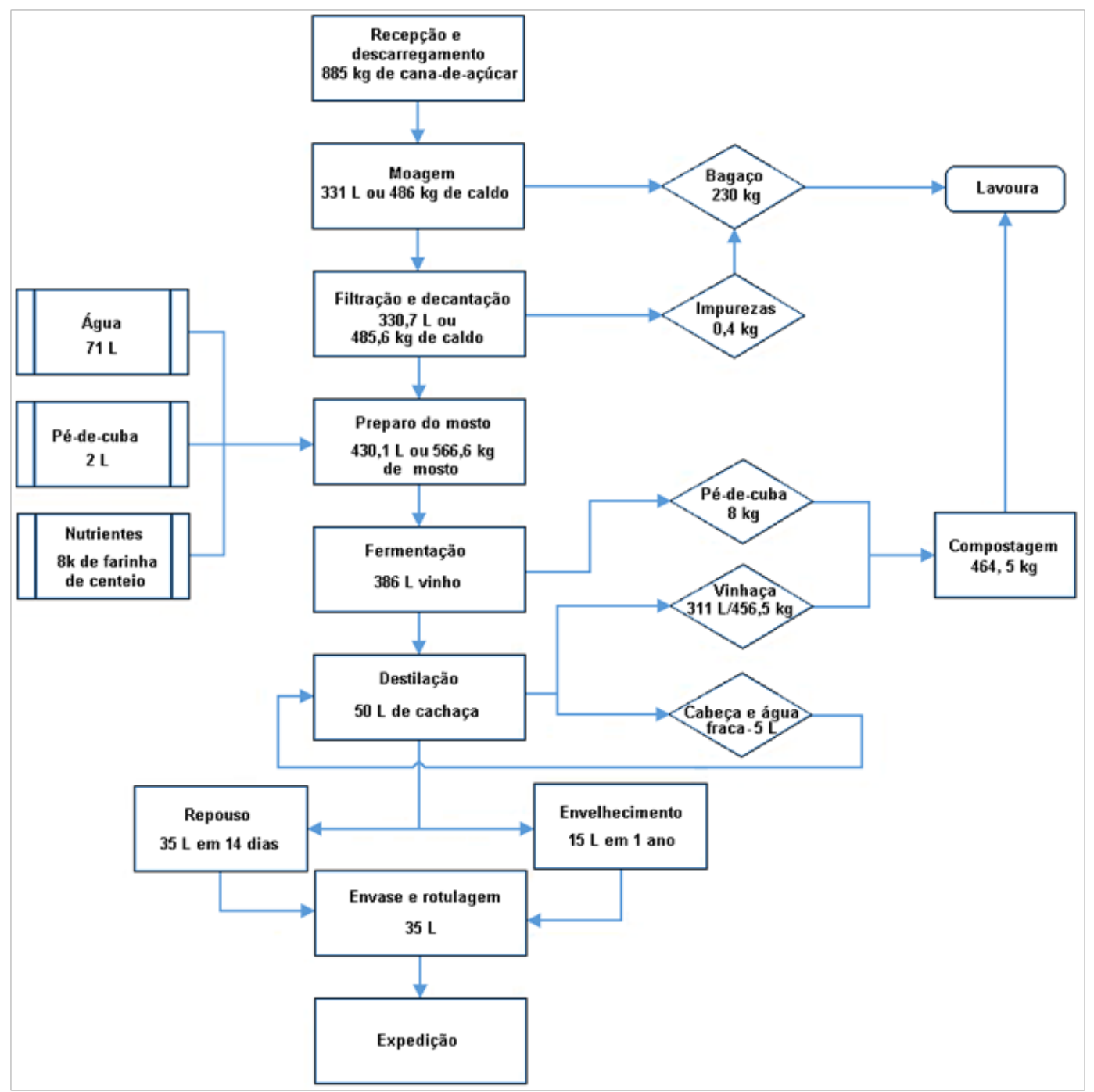

Figura 1: Fluxograma e balaço de massa

em menor escala variam seus preços entre $R \$ 20,00$ e 30,00. Cachaças de maior prestígio, que já venceram concursos internacionais, podem chegar a $\mathrm{R} \$ 80,00$ ou mais. Os maiores consumidores são homens entre 40 e 60 anos. Destaca-se a importância dada pelo consumidor ao fato de a cachaça ser artesanal. Já, o fato de a cachaça ser de cana-de-açúcar orgânica, ano de produção/fabricação e propaganda em meios de comunicação são itens muito pouco considerados.

A análise de laboratório demonstrou que a cachaça tipo Prata produzida na propriedade possui teor alcoólico de $44^{\circ} \mathrm{GL}$, já as outras amostras são de cachaça azul, sendo que uma delas apresentou teor de $40^{\circ} \mathrm{GL}$ e a outra de $49^{\circ} \mathrm{GL}$. Para receber a denominação de cachaça, o produto deve apresentar um teor alcoólico de 38 a $48 \%$ de volume de álcool ou na unidade de Gay Lussac corresponde a 38 e $48^{\circ} \mathrm{GL}$. Uma das amostras apresentou teor maior que o permitido, não podendo ser considerada cachaça. Já o produto que pretende-se comercializar está dentro das normas exigidas, conforme a IN No 13 .

A Figura 1 apresenta o fluxograma e o balanço de massa para a produçáo de cachaça do processo em estudo.A mesma demonstra as operações unitárias necessárias para o processo e sua consideração em massa para o estudo em questáo.

A Figura 2 apresenta a proposta de ambientes de produção de cachaça com as modificaçóes e a Figura 3 mostra o rótulo desenvolvido para a cachaça do processo em estudo.

Ainda não há norma específica para instalações de agroindústria de cachaça, sendo assim, optou-se por seguir as recomendações de Souza et al. (2013), pois a Instrução Normativa $N^{\circ} 17$ é genérica para todos os tipos de bebidas a serem processadas.

Embora seja uma agroindústria para agricultura 


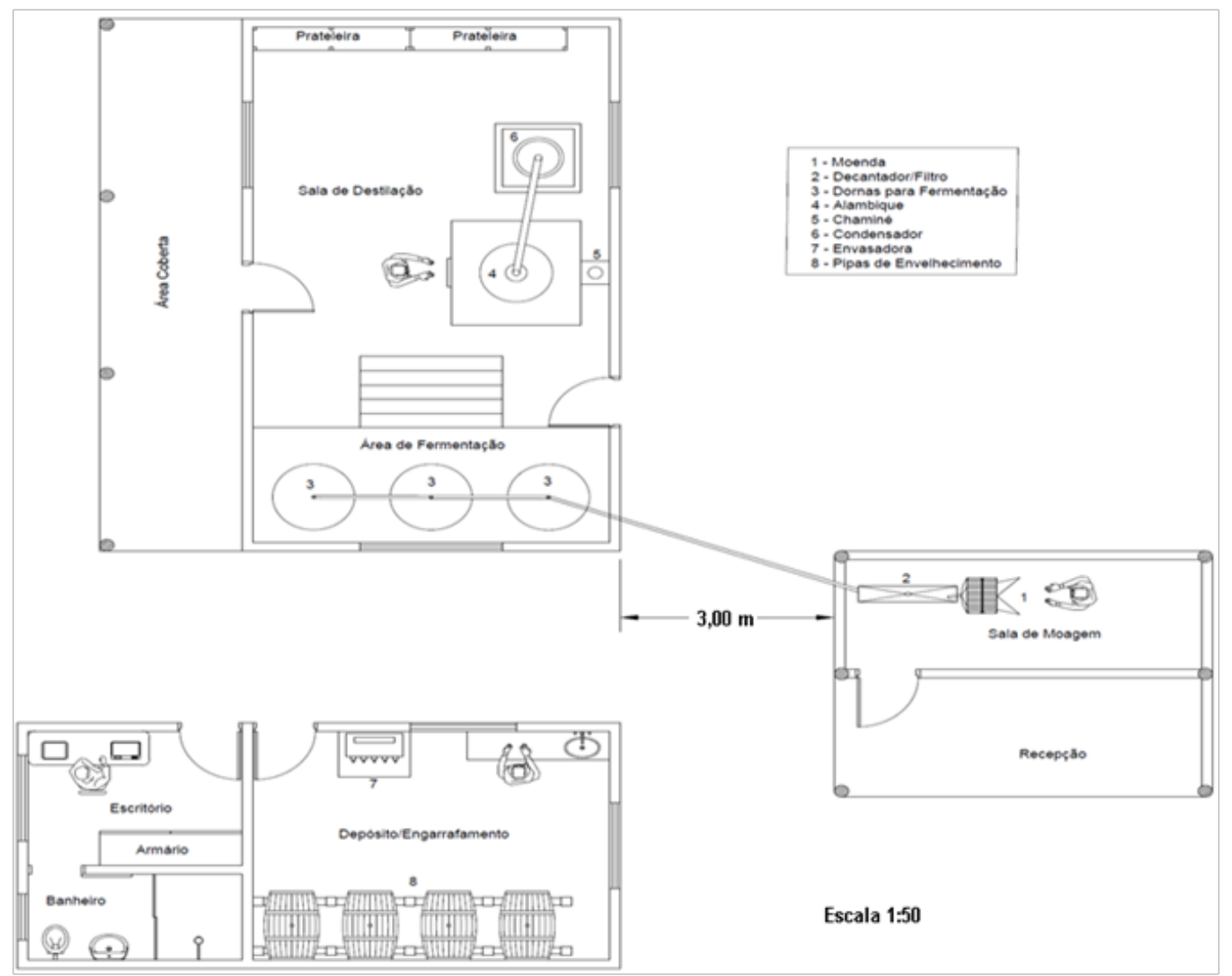

Figura 2: Planta com os ambientes de produção adequados

familiar, também podem ser solicitados na planta baixa os banheiros e vestiários para funcionários, se fosse o caso, bem como os almoxarifados e o local da expedição.

As adequações propostas foram no local de recepção e moagem da cana-de-açúcar, de forma a tornar a moenda, que é movida por tração animal, em elétrica, adequar o piso para cimento bruto e fazer um muro de 1,5 m de altura para impedir o acesso de animais. A sala de fermentação é a mesma da destilação. Este prédio será inteiramente reformado, para adequar-se aos requisitos de higiene e segurança,em função das exigências listadas pelo Ministério da Agricultura, Pecuária e Abastecimento (MAPA),e serão adquiridas novas caixas de água multiuso.Será aproveitada a declividade do terreno para manter as dornas em uma diferença de cota que facilite o trabalho.

Para adequar-se, o armazenamento do produto será em garrafas que serão dispostas em caixas de papelão, o ambiente terá pipas de madeira para o envelhecimento de 30\% da produção de cachaça e será construído um escritório para a administração do negócio.

Os rótulos foram desenvolvidos para atrair o consumidor, tendo um design atrativo e contendo os selos de produto orgânico e de produto proveniente da agricultura familiar. Também foram inseridas as informações obrigatórias para bebidas alcoólicas previstas na legislação e as informações do produto e produtor.

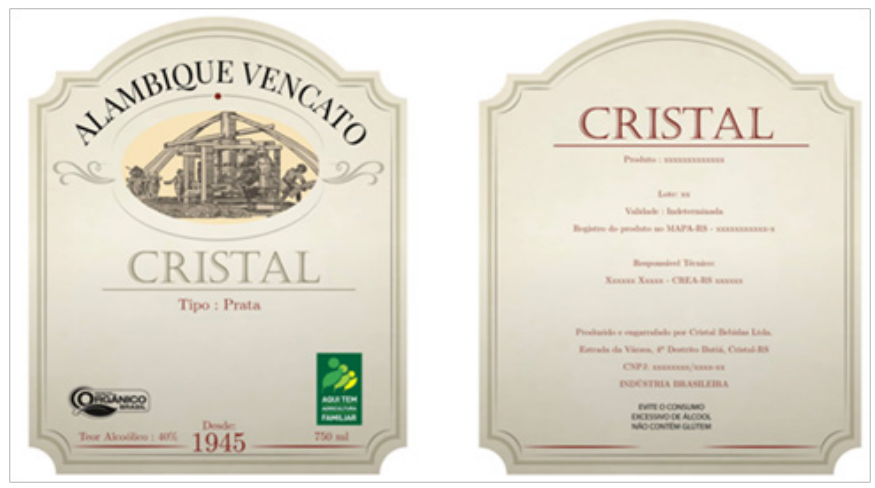

Figura 3: Proposta de rótulo para a cachaça tipo Prata

Considerando a produção de 3500 L/ano de cachaça e a isenção do IPI, seria necessário um investimento total de $\mathrm{R} \$$ 68.502,00, com $100 \%$ deste montante financiado, a juros de $7 \%$ ao ano, pelo sistema SAC e em um prazo de 10 anos. No total do investimento foram considerados os valores de máquinas, equipamentos, instalaçôes e obras civis, além de $2 \%$ de imprevistos. 
A matéria prima é produzida pelo produtor, resultando em baixos custos para a produção. Os custos fixos são baixos quando comparados com os custos variáveis, sendo os maiores valores com embalagens e rótulos, os quais serão atrativos aos consumidores, e será considerado salário mínimo para cada um dos produtores durante os meses de produção, apesar de ser uma atividade familiar. As despesas variáveis e fixas se resumem a fretes e a juros de financiamento.

A análise de SWOT (Figura 4) e o modelo CANVAS (Figura 5) mostraram que, aplicada na agroindústria de cachaça, é possível observar que devido tratar-se de um negócio familiar, a mão-de-obra pode ser um ponto fraco. Por outro lado, não depende de fornecedores de matéria prima para a produção.

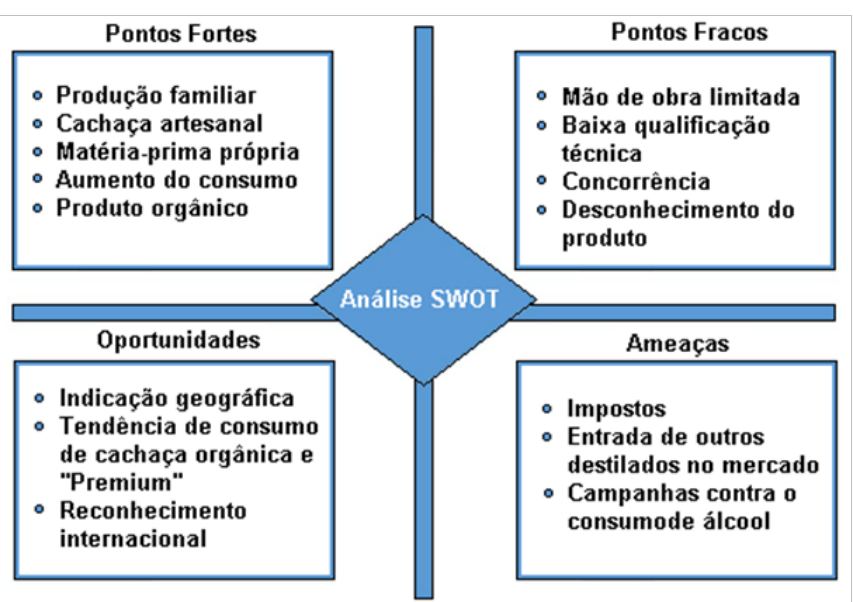

Figura 4: Análise SWOT do projeto agroindustrial de cachaça artesanal
A Tabela 1 apresenta os resultados dos cenários estudados na análise econômica.

Tabela 1 - Índices econômicos dos cenários estudados com TMA a $14 \%$

\begin{tabular}{|l|l|l|l|l|}
\hline Cenários & \multicolumn{4}{l|}{ Índices } \\
\hline & VPL (R\$) & TIR & TIRm & $\begin{array}{l}\text { Payback } \\
\text { (anos) }\end{array}$ \\
\hline pessimista & 6,61 & $14 \%$ & $12 \%$ & 10 \\
\hline real & $32.712,18$ & $71 \%$ & $37 \%$ & 2 \\
\hline otimista & $98.717,37$ & $189 \%$ & $48 \%$ & 1 \\
\hline com IPI* & $4.901,31$ & $18 \%$ & $17 \%$ & 9 \\
\hline
\end{tabular}

(*) Valor do IPI 46\%

O cenário pessimista foi elaborado baseando-se no valor mínimo que o produtor pode vender seu produto em que a TIR igualaria à TMA. Sendo assim, os preços praticados seriam de $\mathrm{R} \$ 23,00$ para a cachaça tipo Prata e de R \$ 34,12para a cachaça envelhecida.Estes valores foram obtidos aproximando a VPL de zero.

No cenário real, considerando o preço de venda um valor médio dos preços praticados pelos principais concorrentes, o valor da cachaça tipo Prata seria $\mathrm{R} \$ 25,00$ e a tipo Premium $\mathrm{R} \$ 45,00$. Este cenário apresenta uma TIR atrativa de $71 \%$ comparada com a TMA de $14 \%$ e um retorno do capital investido em 2 anos.

No cenário otimista, considerando o preço de venda do produto os mesmos que os praticados pelos

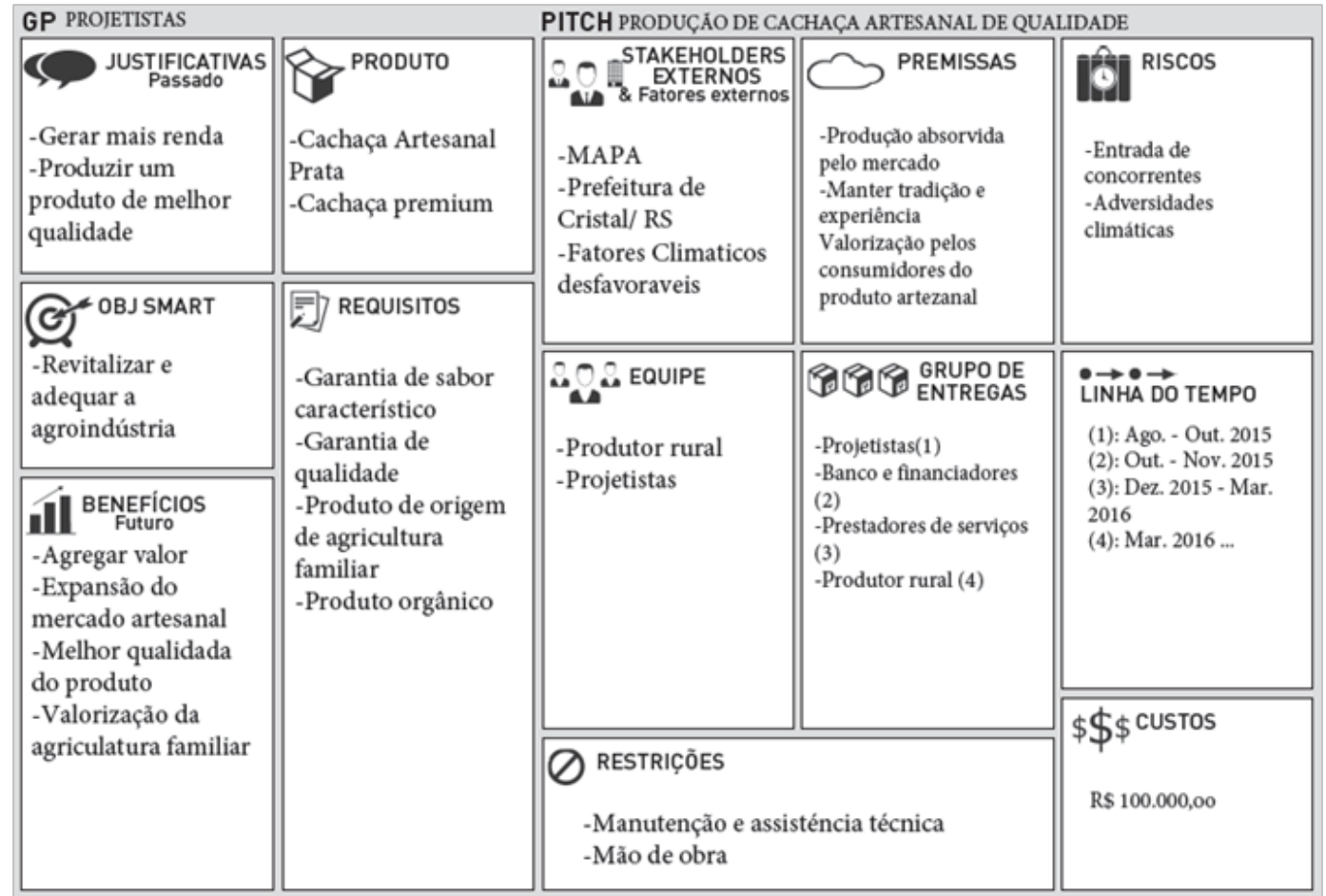

Figura 5: Modelo de negócio Canvas para a agroindústria de cachaça artesanal 
principais concorrentes, ou seja, a cachaça tipo Prata a $\mathrm{R} \$ 30,00$ e a tipo Premiuma $\mathrm{R} \$ 60,00$, a TIR seria de $189 \%$ comparada com a TMA de $14 \%$ e um retorno do capital investido em 1 ano.

AComissão de Agricultura, Pecuária, Abastecimento e Desenvolvimento Rural da Câmara dos Deputados aprovou proposta que isenta do Imposto sobreProdutos Industrializados (IPI) a cachaça artesanal produzida por agricultores familiares. A medida está prevista no Projeto de Lei 1269/15. Os requisitos para a isenção do IPI são que a cachaça seja produzida por agricultor familiar ou empreendedor familiar rural, deverá ser elaborada com pelo menos $70 \%$ de cana-de-açúcar colhida no imóvel e na quantidade máxima de $20 \mathrm{mil}$ litros anuais. Sendo assim, o produtor do estudo em questão, seria isento do imposto.

Apesar de estar em caráter conclusivo, foi elaborado um cenário onde incide sobre a produção o IPI atualmente cobrado. Nota-se o quanto é oneroso para o produtor de pequeno porte a tribução, e esperase que a lei entre em vigor o mais breve possível, beneficiando milhares de produtores de cachaça artesanal, conferindo maior renda a esta atividade da agricultura familiar. Sem a isenção do imposto, a cachaça deve ser vendida no preço de $\mathrm{R} \$ 40,00$ a tipo Prata e de R \$ 80,00 para a tipo Premium, e mesmo com esses preços elevados, a TIR seria de apenas $18 \%$ que é muito abaixo dos outros cenários viáveis observados.

\section{CONCLUSÕES}

As adequaçóes da agroindústria de cachaça artesanal apresentaramviabilidade técnica, mostrando que pequenas modificaçóes podem permitir o enquadramento de um produtor artesanal nas especificaçóes legais.

O estudo de viabilidade econômica da agroindústria de cachaça artesanal apresentou taxas internas de retorno (TIR) distintas nos diferentes cenários, demonstrando a sensibilidade da variaçáo do preço da cachaça na viabilidade do projeto. Comparados com uma TMA de $14 \%$, os cenários apresentaram condições de viabilizar o projeto. Com o preço de venda de $\mathrm{R} \$ 23,00$ para a cachaça tipo Prata e de R\$ 34,12 para a tipo Premium, o projeto equilibrou as finanças, determinando assim o preço mínimo de comercialização para a quantidade produzida. Considerando o IPI há uma redução da TIR para $18 \%$.

\section{REFERÊNCIAS}

BRASIL. Casa Civil. Lei No 11.326, de 24 de julho de 2006. Política Nacional da Agricultura Familiar e Empreendimentos Familiares Rurais. Brasília, 27 de julho de 2006.

BRASIL. Ministério da Agricultura, Pecuária e Abastecimento. Instruçáo Normativa ${ }^{\circ}$ 13, de 29 de junho de 2005. Diário Oficial da Uniāo. Brasília, 30 de junho de 2005.

BRASIL. Ministério da Agricultura, Pecuária e Abastecimento. Instruçáo Normativa ${ }^{\circ}$ 17, de 23 de junho de 2015. Diário Oficial da União. Brasília, 24 de junho de 2015.

BRASIL. Ministério da Agricultura, Pecuária e do Abastecimento. Instruçáo normativa ${ }^{\circ} \mathbf{2 7}$, de 15 de maio de 2008 . Altera o item 9.4 da Instrução Normativa ${ }^{\circ} 13$, de 29 de junho de 2005. Diário Oficial da União. Brasília, 16 maio de2008.

BRASIL. Ministério da Agricultura, Pecuária e do Abastecimento. Instruçáo Normativa ${ }^{\circ} \mathbf{5 8}$, de 19 de dezembro de 2007. Altera os itens 4 e 9, do Anexo, da Instrução Normativa ${ }^{\circ} 13$, de 29 de junho de 2005. Diário Oficial da República Federativa do Brasil, Brasília, DF, 08 jan. Seção 1, p.5, 2008.

BUARQUE, C. Avaliaçáo econômica de projetos: uma apresentação didática. 6.ed. Rio de Janeiro: Campus, 1991.

CASAROTTO FILHO, N.; KOPITTKE, B.H. Análise de investimentos: matemática financeira, engenharia econômica, tomada de decisão, estratégia empresarial. 9.ed. São Paulo: Atlas, 2000.

IBRAC. Instituto Brasileiro da Cachaça. Disponível em: <http://www.ibrac.net/index.php/servicos/estatisticas/ estabelecimentosregistrados/estabelecimentos-por-estado $>$. Acesso em: 31 ago. 2015.

KOTLER, P. Administração de marketing: análise, planejamento,implementação e controle. 2.ed. São Paulo: Atlas, 1992.

MUTTON, M.J.; MUTTON, M.A. Aguardente de cana. In: VENTURINI FILHO, W.G. Tecnologia de bebidas.São Paulo: Edgard Blücher, 2010. 461p.

OLIVEIRA, C.R. et al. Cachaça de alambique - Manual de Boas Práticas Ambientais e de Produçáo. Belo Horizonte: SEMAD/ FEAM (Convênio de Cooperação Técnica - SEAPA/ SEMAD/AMPAQ/FEAM/IMA), 2005. p.72.

SILVA, C.B.; GUIMARÃES, D.D.; LIMA, E.J. Caracterização e análise da cadeia produtiva da cachaça brasileira. In: CONGRESSO DA SOBER, 43., 2005. Anais... Ribeirão Preto, 2005.

SOUZA, L.M.; ALCARDE, A.R.; LIMA, F.V.; BORTOLETTO, A.M. Produção de cachaça de qualidade. Piracicaba: ESALQ, 2013. p.72. 